Case Report

OOpen Access

CrossMark

\title{
latrogenic perforation of the left ventricle following chest drain insertion
}

\begin{abstract}
Tube thoracotomy placement is a standard procedure for the treatment of pneumothorax and pleural effusions. It's a safe and efficient procedure when correctly done under appropriate indication and technique. Reported complications include infection, vascular injury with bleeding, and injury to the lung, liver, diaphragm, stomach, spleen and heart. We report a rare complication of left ventricle perforation after chest drain placement and the role of transthoracic echocardiography with contrast in the early diagnosis of this serious complication.
\end{abstract}

Keywords: complication of chest drain, left ventricle perforation, pleural effusion
Volume 9 Issue 4 - 2017

\begin{abstract}
Abdullah J Alsaiedi,' José Andres Fernandez, ${ }^{2}$ Mazhar Ur Rehman, ${ }^{3}$ Saad AI Bugami ${ }^{4}$

'MD Cardiology Fellow, King Faisal Cardiac Centre, King Saud Bin Abdulaziz Medical City, Jeddah, Saudi Arabia ${ }^{2} \mathrm{MD}$, Consultant Cardiac Anaesthesia, King Faisal Cardiac Centre, King Abdulaziz Medical City, Jeddah, Saudi Arabia ${ }^{3}$ MD, FRCS, FRCS-CTh, Consultant Cardiac Surgery, King Faisal Cardiac Centre, King Abdulaziz Medical City, Jeddah, Saudi Arabia

${ }^{4} \mathrm{MD}$, FACC, FSCAI, Consultant Adult Congenital and Structural Heart Disease Intervention, King Faisal Cardiac Centre, King Saud Bin Abdulaziz Medical City, Jeddah, Saudi Arabia
\end{abstract}

Correspondence: Saad Al Bugami, King Saud Bin Abdulaziz University, King Abdulaziz Medical City, King Faisal Cardiac center, Jeddah 21423, Saudi Arabia, Tel 9665055I6952, Email bogamisa@ngha.med.sa

Received: July 26, 2017 | Published: August 10, 2017

\section{Case history}

57- year-old women underwent 2 vessel coronary artery bypass grafting $(\mathrm{CABG})$, Mechanical mitral valve replacement and tricuspid valve repair. She required a chest drain insertion for worsening left sided pleural effusion this was done in the surgical intensive care unit using a $12 \mathrm{~F}$ pig tail. Shortly following the insertion she started to become breathless and hemodynamically compromised with a drop of her blood pressure and oxygen saturation. It was noted that the chest drain was draining frank blood which was clamped. Chest x-ray revealed an abnormal position of the drain across the heart (Figure 1). Bed side echocardiogram showed the drain traversing the left ventricle (Figure 2). Bubble study through the chest drain showed contrast bubbles inside the left ventricle confirming position of the drain and perforation of the left ventricle (Figure 3). The drain was kept in situ. She was taken to the operating theatre for an emergency left thoracotomy. It appeared that the drain was penetrating the left lung and the left ventricle (Figure 4).

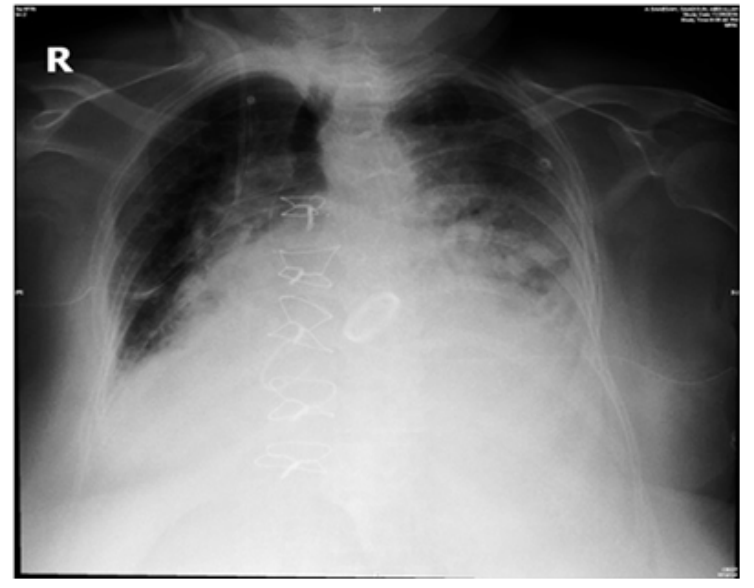

Figure I Chest X- ray showing the chest tube crossing the heart.

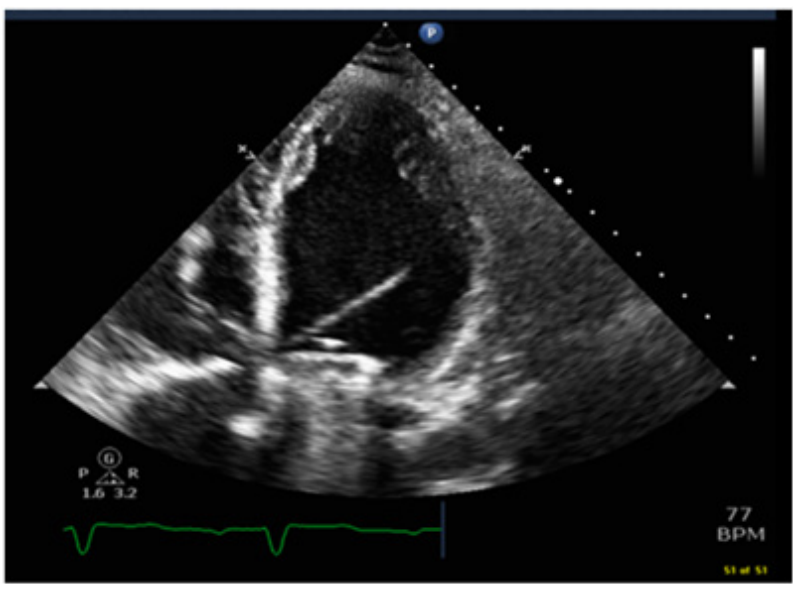

Figure 2 Arrow points to the chest tube drain traversing the left ventricle.

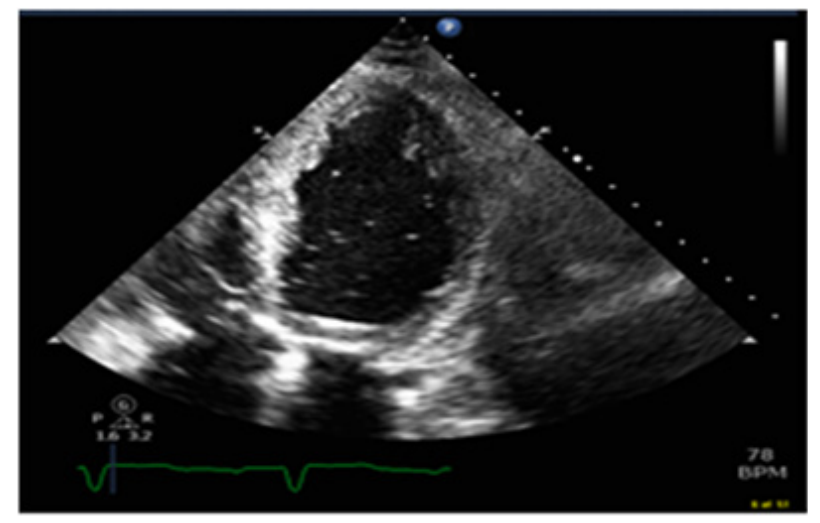

Figure 3 Bubbles inside the left ventricle to ascertain position of the chest drain. 


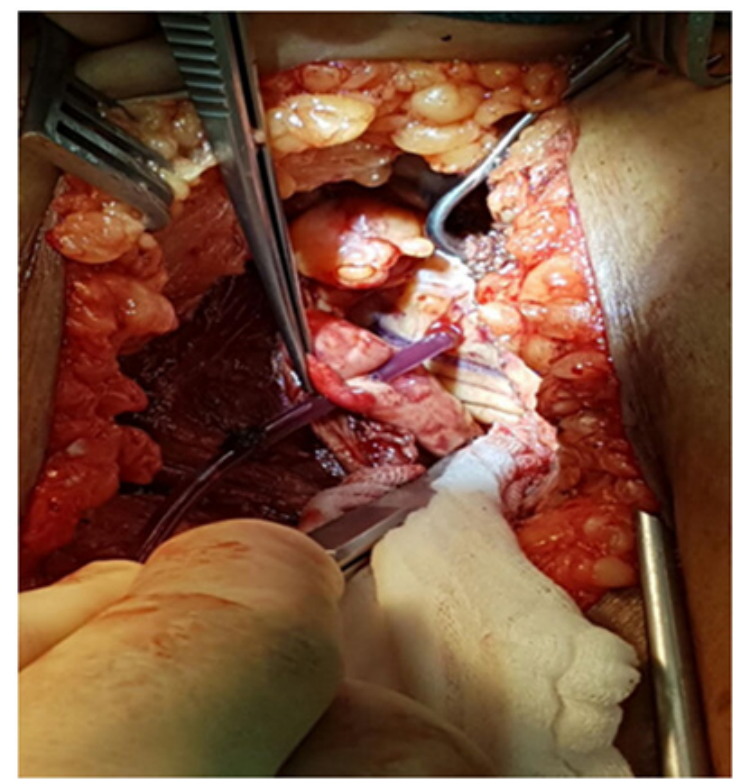

Figure 4 Left thoracotomy showing the chest tube drain penetrating the left lung and the left ventricle.

The chest drain was removed and closure of the left ventricle perforation was secured with pledgets. She was observed in surgical intensive unit for a few days. Postoperative course was unremarkable she was later discharged home.

\section{Discussion}

Chest drain insertion is a commonly used invasive procedure for managing pneumothorax and draining the pleural cavity. It is also performed for patients with pleural effusion and Empyema. ${ }^{1}$ It is widely used throughout the medical, surgical, and critical care specialities. It may be associated with certain complications such as infection, bleeding, and injury to the adjacent organs. ${ }^{2}$ Major complications to the lung, heart, great vessels or other vital organs caused by a chest tube insertion may reach $30 \%$ but are rare in the hands of experienced physicians. ${ }^{3} \mathrm{~A}$ heart perforation during chest drain placement is a very rare complication that, to our knowledge, has been described in only ten publications to date. ${ }^{4}$ Only three of the ten published heart perforations survived.

Major complications, including laceration or perforation of major organs, are usually related to trochar usage and improper blind technique and failing to identify important landmarks for insertion. The insertion should be done within the safety triangle, which is marked by the anterior border of the latissimus dorsi muscle, the lateral border of the pectoralis major, a horizontal line above nipple level, and an apex below the axilla. ${ }^{1}$ Most cardiac injuries during the procedure were related to anatomic distortion such as post-pneumonectomy, extreme kyphoscoliosis, and cardiomegaly. ${ }^{5-8}$ Our patient had marked cardiomegaly which made the left heart border close to the chest wall another factor was the avoidance of the use of image guidance.
It was proposed that the safest way to place a small-sized chest drain correctly is by using image guidance by ultrasound or computed tomography. If however the heart is perforated, the drain must be clamped and computed tomography be obtained immediately as long as the patient is in a stable hemodynamic condition. If the patient is hemodynamically unstable then a transthoracic echocardiography with contrast would be great diagnostic modality as in this situation by demonstration of "bubbles" in the perforated cardiac chamber following agitated saline injection through the chest drain. Emergency thoracotomy is the treatment of choice in this type of complication.

\section{Conclusion}

The insertion of chest drain is a safe procedure when introduced correctly and under image guidance. We believe it's mandatory to identify anatomical land mark and use image guidance to avoid catastrophic complication even when using a small sized drain in nonlife threating situation.

\section{Conflicting interest (If present, give more details)}

The authors declare no conflict of interest.

\section{Acknowledgements}

None.

\section{Funding}

None.

\section{References}

1. Laws D, Neville E, Duffy J. Pleural Diseases Group, Standards of Care Committee, British Thoracic Society. BTS guidelines for the insertion of a chest drain. Thorax. 2003; 58 (Suppl 2):1-59.

2. Collop NA, Kim S, Sahn SA. Analysis of tube thoracostomy performed by pulmonologists at a teaching hospital. Chest. 1997;112(3):709-713.

3. Kerger H, Blaettner T, Froehlich C, et al. Perforation of the left atrium by a chest tube in a patient with ardiomegaly: management of a rare, but life-threatening complication. Resuscitation. 2007;74(1):178-182.

4. Dongmin Kim, Seong-Hoon Lim, Pil Won Seo. Iatrogenic Perforation of the Left Ventricle during Insertion of a Chest Drain. Korean J Thorac Cardiovasc Surg. 2013;46(3):223-225.

5. Asopa S, Iyenger S, Lloyd CT, et al. Accidental perforation of the left ventricle with a Bonannocatheter. J Thorac Cardiovasc Surg. 2009;137(4):1023-1024.

6. Goltz JP, Gorski A, Bohler J, et al. Iatrogenic perforation of the left heart during placement of a chest drain. Diagn Interv Radiol. 2011;17(3):229-231

7. Kopec SE, Conlan AA, Irwin RS. Perforation of the right ventricle: a comlication of blind placement of a chest tube into the postpneumonectomy space. Chest. 1998; 114(4):1213-1215.

8. Meisel S, Ram Z, Priel I, et al. Another complication of thoracostomy: perforation of the right atrium. Chest . 1990;98(3):772-773. 